\title{
Historiografía, cooperación internacional y solidaridad americana. E1 II Congreso Internacional de Historia de América y el rol de la historia en la construcción de una identidad continental
}

Martha Rodriguez*

\section{Resumen}

Es harto frecuente vincular el proceso de construcción de los estados nacionales y su necesidad de generar identidades de carácter nacional con la progresiva constitución de un campo historiográfico. En ambos los historiadores cumplían un rol central, como garantes de una historia científica pero también como usina y transmisores de relatos identitarios.

La dimensión centralmente nacional de esta empresa historiográfica convivió con esfuerzos y voluntades de trascenderla, aun cuando el fondo identitario perviviera en las motivaciones. En la Argentina de los años '20 y '30, fue evidente el esfuerzo de sus más conspicuos representantes por estimular investigaciones y docencia que abrieran los marcos nacionales a los confines continentales. Esta operación fue entendida no solo como un aporte al conocimiento histórico, sino más allá de cuestiones estrictamente disciplinares, como una faceta de la cooperación entre estados. Y es en este sentido que puede pensarse como un instrumento de política internacional.

En esta presentación nos proponemos analizar el II Congreso Internacional de Historia de América desarrollado en Buenos Aires en 1937. Organizado por la Junta de Historia y Numismática Americana como parte de los festejos por el Cuarto Centenario de la Ciudad de Buenos Aires, el evento desbordó el mundo académico para conjugar también diplomacia y política. En su seno se presentaron argumentos que, más allá de su pertinencia historiográfica o la calidad de las investigaciones que los sustentaban, reforzaron ciertos sentidos sobre la identidad americana, la

\footnotetext{
* Universidad de Buenos Aires. CONICET. E mail: mrod@fibertel.com.ar
} 
cooperación internacional, y especialmente, sobre la función de los historiadores y su saber en esos procesos.

Palabras Clave: Historiografia - Historia de América - Cooperación internacional

\section{Summary}

It is not uncommon to link the process of the construction of national states and their need to generate national identities with the progressive constitution of a historiographical field. Historians played a central role in both, as the guarantors of a scientific history, but also as the originators and transmitters of identity narratives. The centrally national dimension of this historiographical enterprise coexisted with efforts and wills to transcend it, even though the identity-based background remained in the motivations. In Argentina during the 1920s and 1930s, the effort of its most conspicuous representatives to stimulate research and teaching that would open national frameworks to continental borders was evident. This operation was seen not only as a contribution to historical knowledge, but also, beyond strict disciplinary issues, as a facet of cooperation between states. Thus, it is in this sense that it can be regarded as an instrument of international politics.

Here, we intend to analyse the II International Congress on the History of America held in Buenos Aires in 1937. Organised by the Junta de Historia y Numismática Americana as part of the celebrations for the 400th anniversary of the city of Buenos Aires, the event went beyond the academic world to combine diplomacy and politics. Arguments were presented that, beyond their historiographical relevance or the quality of the research that underpinned them, reinforced certain meanings about American identity, international cooperation and, especially, the role of historians and their knowledge on these processes.

Keywords: Historiography - History of America - International Cooperation

\section{Introducción}

Es harto frecuente vincular el proceso de construcción de los estados nacionales y su necesidad de generar identidades de carácter nacional homogéneas con la progresiva constitución de un campo historiográfico. Las demandas estatales dieron impulso a un proceso de profesionalización disciplinar - que no se reduce a ellas-, en el que se conjugaron sin conflicto aparente la búsqueda de la objetividad con el impulso cívico. Los historiadores cumplieron en esto un rol central como garantes de una historia científica pero también como usina y transmisores de relatos identitarios. El formato historiográfico privilegiado para esta tarea fue la historia nacional, una versión integral del pasado que brindaba un gran relato en el cual reconocerse. El consenso sobre las virtudes pedagógicas y la necesidad de "...Realizar la educación moral de la juventud con la 
enseñanza de la historia..." era amplio, lo mismo que aquel sobre la necesidad de que se realizara fundamentalmente a partir de la difusión en el sistema educativo de las investigaciones desarrolladas en los claustros académicos. ${ }^{2}$

Sin embargo, la dimensión centralmente nacional de esta empresa historiográfica visible en el formato historiográfico "historia nacional" privilegiado por sus cultores-, convivió con esfuerzos y voluntades de trascenderla, aun cuando el fondo identitario perviviera en las motivaciones. En el caso argentino, por ejemplo, fue evidente durante las décadas de 1920 y 1930 el esfuerzo de sus más conspicuos representantes por estimular investigaciones y docencia que permitieran la apertura de lo nacional a lo americano, de los marcos nacionales a los confines continentales. Esta empresa no solo se entendía como un aporte al conocimiento histórico y al ámbito profesional sino como una arista importante de la cooperación internacional y de la defensa de los ideales de solidaridad manifestados por los estados americanos en esas décadas. En este sentido es que puede reflexionarse sobre su uso como un instrumento blando de política internacional, o tal como lo planteamos, como una suerte de embajada historiográfica destinada a reforzar la identidad americana en el continente.

1 Levene R. 1912, Lecciones de Historia Argentina, Ed. Lajouane, Buenos Aires.

2 Con luces y sombras, este proceso de profesionalización estuvo plenamente desplegado en la argentina de los años '30. Alcanzó en ese momento su consolidación un sistema de relaciones académicas, personales e institucionales controladas por los miembros de la denominada Nueva Escuela Histórica, generación que había liderado el proceso de profesionalización. Aunque este proceso reconoce antecedentes, desde mediados de la década de 1920 y con más énfasis durante la de 1930, gobiernos radicales y luego -y especialmente- conservadores estimularon la creación de instituciones, comisiones oficiales y proyectos destinados a fortalecer la conciencia histórica nacional. Los historiadores respondieron a esa demanda encabezando la organización de archivos históricos en todo el país, la redacción de obras de síntesis de la historia argentina, la preservación del patrimonio histórico, la reglamentación de la enseñanza de la historia en la escuela, la revisión de los libros de texto de historia y geografía y la profundización de los vínculos entre pares y con el sistema educativo a través de la organización de congresos y reuniones especializadas. En esas décadas se crean el Archivo Histórico de la Provincia de Buenos Aires, el Instituto de Investigaciones Históricas de la Facultad de Filosofía y Letras de la Universidad de Buenos Aires, la Comisión Revisora de Libros de Texto de Historia y Geografía Americana, la Comisión Nacional de Museos, Monumentos y Lugares Históricos, el Centro de Estudios Históricos de la Universidad de La Plata, la Sociedad de Historia Argentina. La Junta de Historia y Numismática se convierte en Academia Nacional de la Historia en 1938. Para un análisis de la articulación entre historia y política en los años '30 puede consultarse Cattaruzza A. 2001, "Descifrando pasados: debates y representaciones de la historia nacional", en Id. (Dir), Crisis económica, avance del Estado e incertidumbre política, Sudamericana, Buenos Aires. T VII. 
Esta faceta americanista del proyecto historiográfico de la generación que lideró el proceso de profesionalización de la historia en la argentina fue poco estudiada, aunque existe un rico material disponible para rastrear estos aspectos. En esta presentación proponemos reflexionar sobre sentidos e interpretaciones del pasado americano construidas y enunciadas desde el campo historiográfico pero cuyo impacto trascendió las fronteras del mundo académico para alcanzar otros ámbitos, dando cuenta de unos usos de la historia que vinculan la actividad académica y profesional de los historiadores con el mundo extrahistoriográfico. Para ello analizaremos un evento académico en el que se conjugaron dimensiones estrictamente profesionales con otras conmemorativas, políticas y diplomáticas. Se trata del II Congreso Internacional de Historia de América desarrollado en Buenos Aires en 1937. Organizado por la Junta de Historia y Numismática Americana como parte de los festejos por el Cuarto Centenario de la Ciudad de Buenos Aires, en su seno se presentaron y debatieron argumentos que, más allá de su pertinencia historiográfica o la calidad de las investigaciones que los sustentaban, permitieron legitimar ciertos sentidos sobre la identidad americana, la cooperación internacional, sobre el rol pasado y futuro del continente en el concierto internacional de naciones y especialmente sobre la función de los historiadores y su saber en esos procesos.

\section{Tolerancia, pacifismo y cooperación en el mundo de entreguerras: algunas tareas para la historia}

El fin de la primera guerra mundial generalizó ciertas imágenes asociadas al decadentismo de la vieja Europa conmovida en sus cimientos por la guerra y, por contraste, a un continente americano joven, pleno de potencialidades y promesas de futuro. En ciertos núcleos intelectuales el fracaso civilizatorio europeo que había culminado en la gran guerra abría la oportunidad para América de asumir un liderazgo civilizatorio ante el mundo, sea en sus variantes latinoamericanista, panamericanista, hispanoamericanista o indoamericanista.

Lo cierto es que en este clima -y al amparo de las reflexiones abiertas no solo por la primera guerra mundial sino también por el ascenso de los fascismos, la exaltación 
desmesurada del nacionalismo y la rivalidad entre naciones-, los fenómenos vinculados con la creación y difusión de esas ideas en los imaginarios sociales ganaron espacio no solo en el mundo intelectual sino también en las políticas públicas llevadas adelante por distintos estados y por organismos de cooperación internacional. El despliegue de estas reflexiones y políticas destinadas centralmente a diluir las rivalidades entre naciones impulsaron a varios estados europeos y americanos a sellar acuerdos internacionales, crear comisiones nacionales para estudiar los contenidos transmitidos por la escuela y los libros de texto, realizar congresos, conferencias y reuniones internacionales dedicadas al estudio de estos problemas ${ }^{3}$.

La construcción de esta diplomacia cultural se desplegó en América a lo largo de las décadas de 1920 y 1930 con particular intensidad. ${ }^{4}$ En ese marco, los historiadores ocuparon un lugar destacado como asesores, miembros o propulsores de iniciativas destinadas a orientar la cultura histórica de los pueblos americanos hacia una comprensión mutua de sus raíces comunes. Sin dejar de lado la centralidad de la historia nacional, se apuntaba a posicionarla en el contexto de la historia universal y especialmente de la americana. La investigación y critica de la historia del pasado del

3 Para una descripción pormenorizada de las tentativas internacionales destinadas a estudiar los contenidos transmitidos por la escuela, los textos escolares y otros materiales luego de la primera guerra mundial puede consultarse el informe de UNESCO, 1951, La reforma de los manuales escolares y del material de enseñanza. Como ponerlos al servicio de la comprensión internacional, Paris. Por otro lado, la relevancia de los congresos científicos no solo como caja de reverberación de la estructuración y transformación de los campos profesionales sino como ámbito donde se dirimen también proyectos políticos, donde se gestionan sutilmente -o no tanto- cuestiones diplomáticas y donde dirigentes de países organizadores e invitados se implican al lado de los profesionales en la organización del evento ha sido ya señalada. Remitimos aquí a Blänsdorf A., 2010, "Une collaboration scientifique 'dans un esprit vraiment œcuménique et international': Les congrès internationaux d'historiens et le Comité International des Sciences Historiques dans l'Entre-deux-guerres", en Revue Germanique Internationale, n. 12, pp. 209-228; Erdmann K. 2005, Toward a Global Community of Historians: The International Historical Congresses and the International Committee of Historical Sciences, 18982000. Kocka J.y Mommsen W. (Ed) in collaboration with Agnes Blänsdorf . New York: Berghahn Books; Hübinger G., Picht B., Dabrowska E. 2010, Cultures historiques et politique scientifique. Les congrès internationaux des historiens avant la Première Guerre mondiale, en Revue germanique internationale, n. 12, pp. 175-191; Rodriguez M. 2018, "De historiadores y de los posibles usos de su saber: la contribución de los Congresos Internacionales de Historia de América en la conformación de una identidad americana (décadas de 1930 a 1960)", en História da Historiografia, N$^{\circ}$ 27, mai-ago, pp.91-117

4 Para un análisis de las relaciones político- -culturales entre Europa y América Latina en este período, ver Pernet C. 2007, "La cultura como política. Los intercambios culturales entre Europa y América Latina en los años de entreguerras.” Puente@Europa. Noticias de Europa, noticias de América Latina, año V, n. 3-4; para aquellas establecidas entre EEUU y América Latina puede consultarse entre otros Pita Gonzalez A. 2017, "Panamericanismo y Nación. La perspectiva de Samuel G. Inman". Anuario IEHS, n. 32. 
continente permitirían conjugar lo nacional con lo americano rescatando esa historia común que confería un sustrato a la voluntad de convergencia diplomática del presente.

Desde mediados de la década de 1920', pero con mayor énfasis desde los años '30, en la argentina esa diplomacia cultural fue potenciada por la voluntad política y el esfuerzo diplomático tendiente a otorgarle al país protagonismo en la arena internacional especialmente la americana-. Y, simultáneamente, también por el trabajo de un conjunto de historiadores, especialmente aquellos nucleados en la Junta de Historia y Numismática Americana (JHNA) liderada por Ricardo Levene, destinado a intervenir en la construcción de una memoria pública nacional a través de una operación que incluía empeños en diferentes proyectos, desde la redacción de una obra histórica de síntesis de la historia nacional, hasta el trabajo con el sistema educativo, museos, monumentos y sitios históricos; y especialmente, el impulso para convertir a la Institución en un espacio oficial (la Academia Nacional de la Historia). ${ }^{5}$

El espacio ganado por la JHNA y sus historiadores era el resultado de esfuerzos por posicionarse en un campo historiográfico en proceso de consolidación, por lo que la búsqueda del favor estatal se combinó con un trabajo sostenido para estrechar vínculos con espacios historiográficos regionales y locales, y también redes con el exterior, especialmente con el mundo académico iberoamericano, con americanistas franceses y norteamericanos, y desde luego, con las Academias Nacionales. La política de nombramientos de académicos correspondientes tanto en el interior como en el exterior llevada adelante durante los años '30 puede servir como indicador de esta voluntad de liderazgo historiográfico de la institución. Rectores y profesores universitarios, embajadores y funcionarios de alto rango, personalidades destacadas del quehacer historiográfico y del mundo político y cultural se fueron incorporando a una institución que se iba especializando y profesionalizando en sus actividades. ${ }^{6}$

5 Devoto F. 2019, La Academia Nacional de la Historia en sus primeros ochenta años: entre tradición e innovación en ANH, Investigaciones y Ensayos, vol. 67.

6 Girbal Blacha N. 1995, "Renovación y proyección nacional e internacional de la Junta. Ricardo Levene (1927-1931/1934-1938) y la gestión Ramón J. Cárcano y Carlos Correa Luna (1931-1934)” en AAVV, La Junta de Historia y Numismática Americana y el movimiento historiográfico en la Argentina: 18931938, Bs. As., ANH. 
Varios ejemplos abonan lo dicho en los párrafos anteriores. En 1924 Ricardo Levene asistía como delegado del gobierno argentino al Tercer Congreso Científico Panamericano realizado en Lima. ${ }^{7}$ Allí, ante colegas y funcionarios de todo el continente destacaba el valor de la conformación de comisiones nacionales de historiadores para asesorar a los poderes públicos y proponía la creación de una comisión integrada por historiadores para redactar, en el término de tres años, una historia de América que pudiera servir de texto escolar en la escuela media y de vehículo para crear una "verdadera solidaridad continental", educando al mismo tiempo en el culto de la propia patria y en el sentimiento de amor entre los pueblos. Aunque el manual nunca vio la luz, el proyecto fue aprobado en la sesión plenaria y se creó una comisión de cinco historiadores encargados de redactarlo. ${ }^{8}$

En agosto de 1928 los historiadores participantes del I Congreso de Historia Nacional organizado en Montevideo, entre los que había varios argentinos, habían recomendado a los estados americanos estrechar las relaciones que los unían a través de la firma de tratados que contemplaran la revisión de los libros de texto de historia y geografía, instando a priorizar los aspectos vinculados con la unidad histórica, cultural y económica por sobre los conflictos y desavenencias. ${ }^{9}$

En 1933 dos historiadores argentinos, Rómulo Zabala y Enrique de Gandía, miembros de la JHNA pero también respectivamente secretario y co-director de El Monitor de la Educación Común - órgano oficial del Consejo Nacional de Educación-, eran designados delegados de ese Consejo ante el XXV Congreso Internacional de Americanistas celebrado en La Plata. Amparados en esa representación institucional, propusieron con éxito entre los participantes la constitución de un Instituto Internacional para la Enseñanza de la Historia en los países hispanoamericanos, sobre la base de las recomendaciones emanadas de la Conferencia Internacional para la Enseñanza de la Historia realizada en la Haya el año anterior a propósito del rol de los historiadores en esos espacios. Con sede en Buenos Aires, el instituto además de tener a su cargo la

7 Decreto del 18/11/1924 firmado por el presidente Alvear.

8 Tercer Congreso Científico Panamericano, 1938, Acta Final, Lima.

9 Diario Oficial da Uniao, 30/10/1928, pp. 42. Disponible en https://www.jusbrasil.com.br/diarios/2200297/pg-42-secao-1-diario-oficial-da-uniao-dou-de-30-101928 [consultado el 4 de marzo de 2021] 
revisión de manuales y libros de historia, serviría de centro de reunión de historiadores hispanoamericanos, espacio del que se esperaba también la redacción de un manual de historia que pudieran adoptar las naciones del continente.

El proyecto será retomado y cobrará carácter oficial durante la Convención sobre la enseñanza de la historia desarrollada en Montevideo en el marco de la Séptima Conferencia Internacional Americana a fines de 1933. Allí los ministros de Relaciones Exteriores de Argentina, Bolivia, Brasil, Colombia, Cuba, Chile, Ecuador, El Salvador, Estados Unidos, Guatemala, Haití, Honduras, México, Nicaragua, Panamá, Paraguay, Perú, la República Dominicana y Uruguay, enfatizando la necesidad de “...complementar la organización politica y jurídica de la paz con el desarme moral de los pueblos, mediante la revisión de los textos de enseñanza que se utilizan en los diversos países..." aprobaron formalmente la creación de un Instituto para la Enseñanza de la Historia de las Repúblicas Americanas, con sede en Buenos Aires, encargado de coordinar la realización en toda América de esos propósitos ${ }^{10}$. Este proyecto tampoco prosperó en el tiempo, pero la iniciativa y su aval por los Estados Americanos muestra con claridad no solo el papel que los historiadores consideraban suyo en esa coyuntura sino aquel que los poderes públicos habilitaban para ese grupo profesional.

Pocos meses antes de la firma de ese convenio interamericano, en octubre de 1933, a instancias de la Argentina se había rubricado otro de carácter binacional entre ésta y la República de Brasil. Ratificado por los cancilleres Saavedra Lamas y Mello Franco, disponía la revisión periódica de los textos de historia y geografía, “...Depurándolos de aquellos tópicos que sirvan para excitar en el ánimo desprevenido de la juventud, la aversión hacia cualquier pueblo americano...” y quitando de “...Los textos de enseñanza de aquellos tópicos que recuerdan pasiones pretéritas, cuando aún no se habian consolidado perfectamente los cimientos de sus

10 Acta de la Convención sobre la enseñanza de la historia de la Séptima Conferencia Internacional Americana, Montevideo, 1933. Disponible en https://www.dipublico.org/14596/convencion-sobre-laensenanza-de-la-historia-septima-conferencia-internacional-americana-montevideo-1933 [Consultado el 4 de marzo de 2021]. En esa oportunidad la representación norteamericana saludaba calurosamente la incitativa y señalaba la profunda simpatía que despertaba en el gobierno norteamericano los impulsos destinados a fomentar la enseñanza de la historia de las Repúblicas Americanas, y, particularmente a la depuración de los textos de historia, pero que como su sistema educativo compete casi exclusivamente a los gobiernos de los estados y no al federal no rubricaran con su firma el convenio. Éste incluía, además de los señalado, el fomento en cada una de las Repúblicas americanas de la enseñanza de la historia de las demás y la intención de dedicar mayor atención a la historia de España, Portugal, Gran Bretaña y Francia, y de cualesquiera otros países no americanos en aquellos puntos de mayor atingencia con la historia de América. 
nacionalidades...". ${ }^{11} \mathrm{El}$ mecanismo principal para materializar este acuerdo fue la creación de comisiones revisoras de la enseñanza de la historia y geografía americanas en ambos países. $^{12}$

Las tareas desarrolladas por la comisión argentina en sus dos primeros años de vida y la aceptación con que fueron acogidas sus propuestas en el seno del gobierno nacional, estimularon a sus miembros a emprender tareas más ambiciosas. ${ }^{13}$ A mediados de Julio de 1936, su presidente, R. Levene, le propuso al Ministro de Relaciones Exteriores C. Saavedra Lamas aprovechar la Conferencia Interamericana de Consolidación de la Paz que se realizaría en Buenos Aires unos meses más tarde -y que la Argentina entendía como un instrumento de intervención importante en la política internacional continental- para organizar una reunión de delegados de los Ministerios de Instrucción Pública de los países americanos ${ }^{14}$.

11 “Convenio entre la República Argentina y la Republica de los Estados Unidos del Brasil para la revisión de los textos de enseñanza de historia y geografía firmado por los Ministros de Relaciones Exteriores Carlos Saavedra Lamas y A. De Mello Franco", en Levene R. 1932-36, Estudios de Historia Nacional, T. IV. (se trata de tomos armados por el propio autor donde reúne varios de sus artículos y conferencias sobre estos temas, que forman parte de su biblioteca personal).

12 La Comisión Argentina estaba formada por R. Levene, F. Outes, F. Daus, C. Correa Luna y E. Ravignani. A la de Brasil la integraban A. Taunay, J. Serrano, R. Gabaglia, S. Docca, O. Rosa, P. Calmon Moniz de Bittencourt, F. Hermes, R. Mendoça

13 El mismo año de su creación, la Comisión acuerda una serie de proposiciones para la enseñanza de la historia y la geografía que trasciende la revisión de los libros de texto para extenderse a toda la enseñanza de estas disciplinas. Se establecen una serie de criterios a seguir para ambas materias. El gobierno argentino rápidamente adoptó como reglamentación oficial las propuestas de la Comisión. El Ministro de Justicia e Instrucción Pública, Dr. Yriondo, sosteniendo que las proposiciones tenían un acertado fundamento, las difunde a todo el sistema educativo haciéndoselas llegar a cada uno de los profesores de las disciplinas involucradas. La carta que los miembros de la Comisión adjuntaron a cada docente en 1935 con las recomendaciones mencionadas, los convocaba a tener en cuenta en el desarrollo de su actividad "... Los ideales de verdad histórica y solidaridad americana que sustentan, y espera que tales principios adquieran su máxima eficacia en la acción docente y dirigente del Sr. Profesor y no únicamente en los libros de texto..." en Levene R.., 1932-36, Estudios de Historia Nacional, T. IV, pp, 24.

14 Esta Conferencia Interamericana de Consolidación de la Paz había sido propuesta por el presidente norteamericano F. D. Roosevelt, quien inauguró las sesiones junto al presidente Justo el 1 de diciembre de 1936. La presidencia de la conferencia recayó en C. Saavedra Lamas. Enviaron delegados los gobiernos de Paraguay, Honduras, Costa Rica, Venezuela, Perú, El Salvador, México, Brasil, Uruguay, Guatemala, Nicaragua, República Dominicana, Colombia, Panamá, Estados Unidos, Chile, Ecuador, Bolivia, Haití y Cuba. Uno de los ejes centrales de la conferencia fue el reforzamiento de la unidad continental, que esperaba estrecharse merced a la común defensa de formas de gobierno democráticas en un contexto histórico internacional que invitaba a ponerlas en duda.

Poco antes de esta conferencia entre julio y agosto, Levene también había mantenido en Brasil entrevistas con sus pares de la Comisión de Revisión de la enseñanza y con el presidente Getulio Vargas sobre aspectos vinculados a la cultura y la cooperación entre los estados americanos. 
El temario propuesto para la reunión giraba alrededor de la extensión a escala americana del trabajo impulsado por Argentina y Brasil, creando para esos efectos comisiones nacionales en cada uno de los países. También se incluía la posibilidad de organizar una biblioteca de autores americanos con el fin de estimular la difusión de obras destacadas de la literatura, la historia, la ciencia, la política, el derecho y el arte en las escuelas, en los centros culturales y en los de formación docente. ${ }^{15}$

En la sesión plenaria de clausura de esa Conferencia Internacional, el delegado de Venezuela, Dr. Zèrega Fombona, propuso que se incluyera en actas la recomendación a los gobiernos de América de designar a la brevedad representantes para el congreso histórico que se realizaría en Buenos Aires unos meses más tarde. Sostenía que varias de las resoluciones votadas en esa Conferencia, como las de orientación pacífica de la enseñanza, revisión de textos escolares y cooperación intelectual tenían su base material, técnica y moral en ese congreso, por lo que su buen funcionamiento haría más visibles los proyectos de la propia Conferencia Interamericana.

Éstas y otras iniciativas de similar tenor confirman la firme política de intervención de los historiadores en eventos internacionales -especialmente los vinculados al mundo americano-, y la importancia que tuvo esa participación en la agenda pública y en ciertos lineamientos de la política exterior por parte de los elencos gobernantes. Esta diplomacia historiográfica descansaba en la convicción de la importancia del conocimiento acabado de la historia y geografía de las respectivas patrias y de las de América en general por parte de las jóvenes generaciones como antídoto frente a las rivalidades y argamasa de la amistad y la cooperación entre las naciones del continente. Será el II Congreso Internacional de Historia de América al que hacía referencia el representante venezolano, realizado en Buenos Aires entre el 5 y el 14 de julio de 1937, la ocasión en que se desplegará con gran visibilidad y amplitud esta operación centrada en la fundamentación de la unidad histórica que caracterizaría a América.

\section{E1 II Congreso Internacional de Historia de América}

15 Levene R. 1942, La Cultura Histórica, Espasa-Calpe, Buenos Aires, pp 235 
El I Congreso Internacional de Historia de América se había celebrado en Río de Janeiro en septiembre de 1922 como parte de los festejos por la conmemoración del primer centenario de la independencia de ese país. Su organización había sido encomendada al Instituto Histórico y Geográfico Brasileño, una de las primeras instituciones latinoamericanas dedicada al estudio del pasado nacional a partir de una labor erudita y heurística. Desde sus orígenes en 1838 había contado con la protección y el mecenazgo real. En gran medida, fue ese mecenazgo y la legitimidad que le brindó el estado imperial como espacio de enunciación oficial sobre la historia nacional lo que permitió su consolidación y continuidad, convirtiéndose en un modelo institucional para el resto de los países latinoamericanos. ${ }^{16}$

Un conjunto nutrido de naciones - Argentina, Canadá, Colombia, Cuba, Chile, Francia, Guatemala, Inglaterra, México, Nicaragua, Países Bajos, Panamá, Paraguay, Suiza, Uruguay, Venezuela - enviaron representaciones oficiales, al tiempo que por EEUU concurrieron delegados no oficiales que representaban a distintas instituciones académicas. Las comitivas argentinas y norteamericanas fueron las más numerosas y participaron activamente del desarrollo del congreso. Ese fue el contexto en el que se explicitó por primera vez en un congreso de historiadores la idea de redactar una Historia General de América, destinada a destacar los elementos compartidos por la “civilización americana". ${ }^{17} \mathrm{El}$ proyecto no logró concretarse, en gran medida porque su materialización dependía de consensos basados en una política de corte panamericanista muy difíciles de lograr, pero como vimos en los párrafos anteriores,

16 Devoto F., 2008, "La construcción del relato de los orígenes en Argentina, Brasil y Uruguay: las historias nacionales de Varnhagen, Mitre y Bauzà", en Carlos Altamirano (dir.) Historia de los intelectuales en América Latina, Katz editores, Buenos Aires, T I. Sansòn Corbo T., 2014, "Matrices institucionales y metodológicas de la historiografía rioplatense del siglo XIX. El influjo de Brasil", en Confluenze. Rivista di Studi Iberoamericani, Vol 6, No 1, pp. 111-137 y 2015, Despertar en Petrópolis. Andrés Lamas y la influencia de Brasil en la Historia de los Estados de la Cuenca del Plata en el siglo XIX, Montevideo, Sicut Serpentes

17 Paschoal Guimarães L., 2005, "Limites políticos de um projeto intelectual para a integração dos povos do Novo Mundo: o Primeiro Congresso Internacional de História da América (1922)". Topoi, N. 10, pp. 192-212; Nascimento Júnior J.L., 2019, "Considerações sobre a produção historiográfica no primeiro quartel do século XX a partir do I Congresso Internacional de História da América (1922)”, Intelligere, Revista de História Intelectual, nº7, pp. 97-108; Nascimento Júnior J.L., 2018, "O congresso, os anais e a historiografia Apontamentos sobre I Congresso Internacional de História da América (1922)" en Revista Latino-Americana de História, ISSN-e 2238-0620, Vol. 8, No. 20, pp 269-284; Nascimento Júnior J.L., 2019, "Congresso Internacional de História da América (1922): Redes de intelectuais e disciplinarização do conhecimento histórico" en Revista Maracanan, No 21, pp 192-200. 
la propuesta sería retomada una y otra vez por historiadores en los años siguientes con fundamentos y objetivos similares. ${ }^{18}$

La Comisión Organizadora del congreso había invitado al historiador y delegado del gobierno argentino R. Levene a incorporarse al evento en calidad de vicepresidente. A instancia suya, en las sesiones plenarias se decidió que el congreso funcionase con carácter permanente, reuniéndose periódicamente en las capitales de los países americanos, y se designó a Buenos Aires como anfitriona-organizadora del siguiente. El objetivo era convertir ese encuentro en una práctica regular que contribuyera a intensificar los vínculos intelectuales entre los historiadores americanos y al mismo tiempo a estrechar lazos de solidaridad y cooperación entre países.

La fecha prevista para la siguiente edición era el 25 de mayo de 1923 y la Argentina el país elegido como anfitrión y organizador. Sin embargo, problemas de diversa índole conspiraron contra la organización del congreso en ese momento. En 1936 la coyuntura era bien diferente. A la consolidación del campo profesional y el ascenso de sus figuras centrales a posiciones expectables, se sumaba la afinidad de la JHNA con los gobiernos conservadores, especialmente entre Levene, presidente de la institución y A. P. Justo y su gabinete. Por eso no fue sorprendente que una de las actividades principales de la programación oficial del festejo por el IV Centenario de la Ciudad de Buenos Aires recayera en un congreso de historia. ${ }^{19}$

18 Finalmente, bajo la dirección de Ricardo Levene, entre 1940 y 1942 vio la luz una Historia de América en 14 tomos. La edición quedó en manos de una editorial privada, W. M. Jackson Inc., que la publicó simultáneamente en castellano, inglés y portugués. Si bien contaba con el respaldo de la ANH, no era la empresa editorial de carácter oficial impulsada por estados y organismos internacionales que se había propuesto originalmente. Cada tomo de la obra estaba a cargo de uno o dos historiadores especializados en el tema a tratar, la mayoría argentinos, a los que se sumaban algunos americanos. En su conjunto abarcaba desde la historia de los primeros pueblos indígenas del continente hasta el presente. Cfr. Levene R., 1940-1942, Historia de América, Buenos Aires, W. M. Jackson Inc.

19 Los usos de las conmemoraciones en los países latinoamericanos han sido analizados por Pablo Ortemberg en varios trabajos. Aunque sin indagar en congresos científicos ni eventos académicos, estudia los rituales puestos en marcha por los estados con motivo de las conmemoraciones oficiales. Puede consultarse entre otros Ortemberg P.,2015, "Geopolítica de los monumentos: los próceres en los centenarios de Argentina, Chile y Perú (1910-1924)", en Anuario de Estudios Americanos, No72, pp 321-350; y 2014, "Los centenarios patrios en la construcción de alianzas y rivalidades internacionales: los festejos trasandinos de 1910, la estatua de O’Higgins y los bemoles peruanos”, en Anuario de Historia de América Latina, No 51, pp 329-350.

El conjunto de actos previstos como parte de la conmemoración de la primera fundación de la Ciudad de Buenos Aires puede consultarse en Municipalidad de la Capital. Buenos Aires, 1936, IV Centenario de la Primera Fundación. Programa oficial de actos, festejos y agasajos a realizarse. 1536-1936, Buenos 
El II Congreso Internacional de Historia de América se gestó así como una iniciativa de la Junta de Historia y Numismática Americana (elevada al año siguiente al rango de Academia Nacional de la Historia), pero con el carácter poliédrico que le confería su condición simultánea de reunión científica, acto conmemorativo y gestión diplomática. Esta impronta signó el desarrollo del congreso, que pivoteo intermitentemente entre historiografía, conmemoración y política.

La comisión oficial organizadora de los festejos, varios de cuyos miembros eran historiadores y parte activa en la organización del congreso, lo tomó rápidamente como uno de los estandartes de su labor. ${ }^{20}$ Un decreto del presidente Justo lo oficializó sobre la base de su trascendencia como acto conmemorativo, como empresa cultural e historiográfica y como estímulo para la consolidación de la solidaridad continental. ${ }^{21}$ Esa normativa estableció también la designación de los historiadores R. Levene, E. Ravignani y R. Zabala como representantes oficiales, la convocatoria por intermedio del Ministerio de Relaciones Exteriores a las universidades y academias de historia de todos los estados americanos y la invitación a instituciones culturales y escuelas dependientes del Ministerio de Justicia e Instrucción Pública a designar profesores de historia para participar de la sección "Metodología de la Enseñanza de la Historia Americana y Revisión de Textos".22

La comisión organizadora del congreso fue presidida por R. Levene, las vicepresidencias quedaron a cargo de reconocidos historiadores de toda América:

Aires, Fabril. El congreso que analizamos ocupó un lugar importante en esos festejos, aunque se realizó a mediados de 1937, es decir al año siguiente de la conmemoración propiamente dicha.

20 La Comisión oficial del IV Centenario de Buenos Aires estaba presidida por el intendente municipal Mariano de Vedia y Mitre e integrada por los historiadores Ricardo Levene, Emilio Ravignani, Rómulo Zabala, Enrique de Gandía además de directores de bibliotecas, archivos y museos.

21 Decreto del 14/01/1937

22 Una Resolución del Ministerio de Justicia e Instrucción Pública del 10/06/1937 organizó la participación de los docentes en esa sección disponiendo que en los establecimientos de capital y alrededores se designara un representante, lo mismo que en aquellos ubicados en lugares donde existiera un solo instituto dependiente del estado nacional. En lugares donde hubiera más de uno, se pondrían de acuerdo para enviar un docente que asumiría la representación colectiva. A estos delegados se les justificaría con goce de sueldo las inasistencias producidas por la participación en el congreso y se les daría pasajes oficiales de ida y vuelta. Con este estímulo y facilidades la representación del nivel medio del sistema educativo fue alta; además de la Inspección General de Segunda Enseñanza participaron profesores del Instituto del Profesorado Secundario de Buenos Aires y Paraná, de los colegios nacionales, escuelas normales, liceos de señoritas, escuelas industriales, colegios de las universidades, escuelas de comercio, y más de 60 profesores de institutos privados incorporados a la enseñanza oficial. 
Clarence Haring y Percy Alvin (EEUU), Alfonso Reyes y M. Toussaint (Mexico), José Rodríguez (Venezuela), Max Fleiuss y Pedro Calmon (Brasil), Antonio Pons y José Navarro (Ecuador), Felipe Barreda Laos y Horacio Urteaga (Perú), Alcides Arguedas (Bolivia), Luis Barros Borgoño y Domingo Amunàtegui Solar (Chile), Felipe Ferreiro y Mario Espalter (Uruguay), Rómulo Carbia y Emilio Ravignani (Argentina). La comisión se completaba con un conjunto de vocales reclutados entre los miembros de la JHNA, de juntas filiales del interior, directores de museos, archivos nacionales y presidentes de juntas de estudios históricos provinciales.

Desde la convocatoria misma el congreso fue pensado por sus organizadores -y visto por el mundo político, académico y educativo- como instancia de convergencia de una multiplicidad de objetivos. A la reflexión histórica, el estímulo a las investigaciones originales sobre la historia americana y la sociabilidad académica que caracterizan a cualquier congreso científico de ese tenor, se le sumaba en este caso el énfasis concedido a la faceta diplomática, expresada en la defensa de las tradiciones de cada pueblo, en la cooperación y en los ideales de solidaridad entre los estados americanos. Su logro suponía otorgarle especial atención a los aspectos pedagógicos, a la reflexión sobre los métodos y contenidos de la enseñanza de la historia americana y a los libros de texto, vehículos privilegiados de difusión de esos valores. ${ }^{23}$

La condición de posibilidad para la convergencia de estos múltiples objetivos descansaba en la convicción de que la "verdad histórica" era perfectamente compatible con el patriotismo, y éste, bien entendido, maridaba sin dificultades con ideales de factura americana, pues contribuía a desplazar las versiones erradas, sectarias y polemistas que influían negativamente en la construcción de las imágenes del "nosotros" y los "otros". La búsqueda de la objetividad conducía a un tiempo, al desarrollo de un trabajo científico y a la consolidación de una identidad nacional y americana. Investigación, docencia, patriotismo y espíritu americano se entramaban sin dificultad.

23 Levene R. 1938, “Advertencia”, en Academia Nacional de la Historia, II Congreso Internacional de Historia de América, Buenos Aires, ANH, T I, pp 25. 
Tal como estaba previsto, el II Congreso Internacional de Historia de América inició sus sesiones el 5 de julio de 1937 con la presencia de representaciones oficiales de Estados Unidos, México, Guatemala, El Salvador, Colombia, Venezuela, Republica Dominicana Cuba, Nicaragua, Costa Rica, Panamá, Brasil, Ecuador, Perú, Bolivia, Paraguay, Chile, Uruguay. La inauguración se produjo con gran pompa. Las más altas autoridades de la Nación y la Ciudad de Buenos Aires se dieron cita para refrendar la importancia del evento, que se inició con la entonación del himno nacional. El Presidente A. P. Justo, el Ministro de Justicia e Instrucción Pública Jorge de la Torre, el de Interior Manuel Alvarado, el de Agricultura Miguel A. Càrcano, el Intendente Municipal M. De Vedia y Mitre, el Cardenal Primado Monseñor Copello, una cantidad importante de diputados, senadores, miembros del cuerpo diplomático argentino y embajadores de países americanos compartieron la apertura.

Los discursos inaugurales recayeron en el presidente del congreso R. Levene, el Intendente de la Ciudad de Buenos Aires y los tres historiadores invitados de honor, el representante de Estados Unidos Dr. Clarence Haring, el representante de Brasil Dr. Pedro Calmon y el de Chile Dr. Ricardo Donoso. Es difícil no ver en los nombres y procedencia una intención diplomática más allá del capital simbólico que cada uno de ellos tuviera ganado en el campo historiográfico. En todos los discursos los elogios a la organización y los votos por un trabajo fructífero se combinaron con referencias al estado de los estudios históricos y especialmente a la situación internacional y al lugar de América en esa coyuntura.

R. Levene destacaba en su discurso la superación de una etapa en la que la historia del continente se escribía a partir de líneas de tensión que enfrentaban a las naciones, “...Eran los problemas del pasado todavia insolubles, la imagen del héroe palpitante de pasión, una politica contradictoria que no terminaba de definirse y las convulsiones internas que padecían nuestros pueblos..."24. Incluso los textos dedicados a la enseñanza de la historia americana se construían según su opinión sobre errores y omisiones, producidos bien por las limitaciones de modestos maestros bien por la intencionalidad de manifiestos polemistas.

24 Ibidem, pp 29. 
Sin embargo, en la perspectiva del autor, esa situación había empezado a revertirse notoriamente en esos últimos años por el impulso de los historiadores profesionales. Una nueva concepción histórica, apoyada en la aplicación de los métodos eruditos de investigación y crítica, permitía elaborar una historia de las unidades americanas en su diversidad y en su totalidad. $\mathrm{Al}$ mismo tiempo, un nuevo compromiso pedagógico de los historiadores con la cultura histórica contribuía a su difusión. ${ }^{25}$

Por sobre las diferencias geográficas, raciales, económicas y políticas las investigaciones históricas revelaban la unidad histórica de carácter moral que distinguía al mundo americano, fraguada en los tres siglos de la colonia en la que se fue consolidando "...un sistema general americano dentro del cual se generó lentamente la Revolución emancipadora, la independencia que nace de la dominación española, portuguesa e inglesa, aunque va contra ellas..."26. Esa historia compartida era una referencia ineludible para dar cuenta de las relaciones interamericanas en la medida que "...Los Estados libres de este Continente marchan hacia la plena realización de su soberanía económica y espiritual y la historia es la unión entre ellos como fuente eterna de verdad y patriotismo...,27

La idea de una unidad histórica y la consecuente y natural vocación americanista de los países del continente, era reforzada también por los otros oradores. El representante de Estados Unidos, el historiador Clarence Haring afirmaba en su discurso que:

...La América española y la América inglesa son ambas el producto de la frontera. Ambas han estado condicionadas en el pasado de las circunstancias sociales y políticas que acompañan a la conquista material de un continente virgen; ambas encaran los mismos problemas políticos y sociales en el presente... ${ }^{28}$

Más explícito aún, el representante de Brasil, Dr. P. Calmon, movilizaba al auditorio exclamando:

...Bendita sea la América, reunida familiarmente en el hospitalario y noble lar argentino para concertar entre sus historiadores la sana y útil politica del conocimiento verídico y reciproco. Es privilegio de nuestro continente este parentesco

25 Ibidem, pp. 34

26 Ibidem pp 34

27 Ibidem, pp. 35

28 Ibidem, pp. 41 
indisoluble. Es su destino la paz sin resentimientos y la cultura sin prevenciones, que aqui representamos. El sentido de su civilización es una profunda y natural solidaridad entre nuestros países, en cuyo sincronismo adivinamos el mismo drama social, igual aventura creadora, equivalente formación histórica. Somos, en este mundo nuevo, la bumanidad nueva... ${ }^{29}$.

Así, ese pasado colonial y los posteriores movimientos de independencia que con particularidades impactaron en toda américa son señalados como el sustrato común del continente:

...La hora de la reconquista decisiva, de la América para los americanos, sonó en modo semejante. El orden puede ser peregrino: la libertad es nativa (...) Crecimos hombro con hombro. (...) De hecho nos comprendemos tan bien, que nunca un prócer americano, en la victoria o en la desgracia (...) se juagó extranjero en país vecino. Los caballeros medioevales se hermanaban por la cruz; nosotros nos fraternizamos en la liberación... ${ }^{30}$

Esto convertía a la opción americanista -o panamericanista- casi en un destino. El “... 'monroismo' no es, así, una novedad sino una verificación (...) Éramos para los americanos forjados al calor de tantas turbulencias cívicas, la libre América..." 31

Las ideas expresadas en los discursos de apertura sobrevolarán también el trabajo en las distintas sesiones, especialmente la convicción compartida de un espíritu de confraternidad americano sustentado en la necesaria, pero al mismo tiempo históricamente prefigurada, unidad panamericana. Lo interesante es que este énfasis no significó el rechazo a la herencia hispana de los países que la poseían, ni tampoco el debilitamiento de la centralidad concedida a la historia hispana e hispanoamericana tanto en las investigaciones como en la historia escolar. En este contexto, parece más bien el intento de construcción de una identidad de la que se destaca su común aspiración a la libertad frente a las derivas históricas de la situación europea. Las reflexiones expresadas en el congreso no son ajenas a la situación internacional y el panamericanismo mentado resultaba una suerte de talismán democrático frente a los embates de los totalitarismos.

29 Ibidem, pp. 44

30 Ibidem pp. 46

31 Ibidem 
Este sentido, que cruza numerosas presentaciones y debates de los historiadores durante el congreso, es más explícito aún en los discursos de cierre y ágapes organizados por las autoridades nacionales como homenaje. Y aunque éstos son discursos de políticos y no de historiadores, cuestión que no debe soslayarse pues los intereses, prevenciones, operaciones y estrategias son otras, es interesante destacar la cercanía de tópicos y referencias. En la clausura del congreso el Ministro de Justicia e Instrucción Pública felicitaba a los historiadores porque "...Habéis procurado al mundo un ejemplo de confraternidad, en momentos cuyo valor no desconocemos. Las palabras que aqui se han pronunciado (...) al perseguir los ideales de acercamiento común constituyen una riqueza nueva que se incorpora al patrimonio moral de nuestros pueblos... ${ }^{, 32}$

Unos días antes, el presidente Justo había ofrecido un almuerzo a las delegaciones extranjeras y ante los historiadores presentes señalado lo

...altamente auspicioso para nuestro continente y halagador para el sentimiento americano, que en esta hora confusa y obscura de la vida de la bumanidad se congreguen en esta ciudad delegados de todos los países que lo integran, no con el objeto de discutir fórmulas como en los congresos del viejo mundo, para alejar el peligro de guerras que parecen más inminentes después de cada uno de esas reuniones, sino con propósitos de elevada especulación espiritual y de alta cultura... ${ }^{33}$

La coyuntura histórica habilitaba una inversión de esquemas que posicionaba a América y a sus historiadores como faro cultural de la humanidad y a la disciplina histórica como fundamento científico y pedagógico de tal tarea, pues en

...estos graves momentos de honda crisis de espiritu, cuando se predican doctrinas extrañas a nuestro medio, y parece hasta elegante renegar del propio pasado y de sus instituciones (...) la historia debe llamar a la serena reflexión y a la cordura. $Y$ debe enseñar a mirar hacia el porvenir sin abominar del pasado que lo preparó $y$ de las instituciones que nos legaron los fundadores de nuestras nacionalidades, instituciones imperfectas, como toda obra bumana, pero por lo menos, perfectibles... ${ }^{34}$

32 Ibidem, pp 360.

33 Ibidem, pp 363

34 Ibídem, pp 364 
En relación a la estructura del congreso, las diferentes sesiones en que se dividió estuvieron guiadas por un principio de organización temático. ${ }^{35}$ Cada una de ellas estuvo presidida por uno o más historiadores, generalmente miembros de la comisión organizadora; se componía además de dos relatores que tomaban nota de las presentaciones, las preguntas y los debates posteriores para redactar una memoria de la sesión, también de un número variable de expositores que habían sido expresamente invitados en función de sus trayectorias. El funcionamiento pautado se abría con las presentaciones de los expositores luego de las cuales se proponía un espacio de intercambio entre todos los participantes que daba lugar a la elaboración de resoluciones y recomendaciones. En la sesión plenaria de cierre, las conclusiones aprobadas en cada sesión pasaban a integrar el documento final con las recomendaciones del congreso.

Por la centralidad y visibilidad que adquirió nos interesa detenernos aquí en el desarrollo de la sesión "Metodología de la Enseñanza de la Historia y Revisión de Textos". Pues si la historia y los historiadores ocupaban un lugar central en la construcción de fundamentos científicos para un proyecto político-cultural de raíz panamericana, el sistema educativo aparecía como el canal indicado para difundir entre las jóvenes generaciones los resultados alcanzados por tal trabajo. Si los juicios errados, sectarios o injustos, eran los causantes de la animosidad entre estados, la difusión a través de la enseñanza formal de las investigaciones producida en sede académica y según convenciones disciplinares sería un óptimo neutralizador de esas tendencias. ${ }^{36}$ La sesión, una de las tres que poseía el rango de plena junto con las de apertura y cierre, fue la más concurrida de todas las organizadas. En gran medida debido a este carácter plenario que habilitaba la participación de todos los congresales, pero también a la

35 Las sesiones que funcionaron a lo largo del congreso fueron: Historia del Arte; Historia Literaria; Historia Política y Económica; Historia Militar, Naval y Numismática; Metodología de la Enseñanza; Historia Filosófica, Científica y Religiosa; Historia Jurídica y Diplomática; Conceptos e Interpretación de la Historia de América; Fuentes de Historia Americana. Archivos, Museos y Bibliotecas.

36 Sobre la relación entre historiografía e historia escolar a lo largo del siglo XX puede consultarse Lewkowicz M. y Rodriguez M. 2016, "Historiografía académica e historia escolar. Los libros de texto de historia entre dos centenarios", en História da Historiografia. Ouro Preto /Edufop, N²0, pp. 4868. 
presencia de docentes convocados desde el ministerio para participar en ella. Sin embargo, no fue sólo el peso cuantitativo el que le otorgó centralidad. El repaso de la nómina de autoridades y participantes de la sesión demuestra la relevancia que este tema poseía para los historiadores, para la JHNA -organizadora del congreso- y para las autoridades nacionales y provinciales. La presidencia recayó en R. Levene y E. Ravignani, en ese momento los dos historiadores argentinos con mayor capital simbólico en la profesión. Los expositores convocados para disertar provenían del campo de la historia o la pedagogía, pero compartían además el desempeño de cargos de gestión en el ámbito educativo: Felipe Barreda Laos era embajador de Perú en Buenos Aires y se había desempeñado con anterioridad como titular de la cátedra de Historia de América de la Universidad de San Marcos; Juan Mantovani, era Inspector Nacional de Segunda Enseñanza, Julio Raffo de la Reta se desempeñaba como Director General de Escuelas de la Provincia de Mendoza y Juan Cassani ocupaba el cargo de Director del Instituto de Didáctica de la Universidad de Buenos Aires. ${ }^{37}$

Los expositores describieron la situación de la enseñanza de la historia de América particularizando cada uno en la realidad de su país de origen. Más allá de las diferencias de estilo, forma y situación contextual, todos coincidían en la necesidad de reformar la enseñanza de la historia y la geografía con el propósito de:

...Atenuar el espiritu bélico e insistir en la cultura de los pueblos (...) Eliminar los paralelos entre los personajes históricos, nacionales y extranjeros y los comentarios y conceptos ofensivos para otros países (...) Evitar que el relato de las victorias alcanzadas sobre las otras naciones pueda servir de motivo para rebajar el concepto moral de los países vencidos (...) No juzgar con odio o falsear los hechos en el relato de guerras o batallas cuyos resultados hayan sido adversos...” $\mathrm{y}$

37 La organización del congreso había dado la posibilidad a los participantes de enviar con anterioridad comunicaciones y propuestas para las sesiones en las que iban a participar. Algunos de los miembros de la comisión organizadora usaron este mecanismo para presentar sus aportes en las mesas en las que no participaban como oradores. Las mismas eran expuestas en forma muy sumaria por los relatores, quienes en el caso de que fueran propuestas, las sometían a la votación general de los presentes. En el caso de la que estamos analizando las comunicaciones presentadas fueron: José $M$. H. Albarracin, "La enseñanza de la historia patria y americana"; Rafael Altamira, " Comunicación relativa a la revisión de textos"; Pedro Calmon, "Cómo enseñar la nueva historia en el Brasil"; Napoleón Gil, "Tahuantinsuyo prehistórico. (Antigüedad de las culturas peruanas)"; Carlos Heras, "La enseñanza de la Historia americana contemporánea"; Ricardo Levene, "La reforma de la enseñanza de la Historia americana y nacional"; Alberto Palcos, "La Historia de América y la educación de la juventud"; C. Parra Pérez, "Memoria sobre la revisión de los manuales de enseñanza"; Cecilia Quiroga de San Martín, "Enseñanza de la Historia". 
en general "...Destacar cuanto contribuya constructivamente a la inteligencia y cooperación de los países americanos..." ${ }^{38}$

A difundir esta idea, tenían que contribuir también los manuales de historia, y para ello era imprescindible acordar criterios y normas comunes para su redacción y especialmente eliminar todo juicio o expresión sectaria o injusta.

Como buenos herederos de la tradición erudita estos historiadores no consideraban que estas reformas pudieran atentar contra los fundamentos científicos de la práctica historiográfica, ya que según su opinión “...No se trata de suprimir la mención de guerras o conflictos diplomáticos, sino de exponer el pasado con un criterio objetivo, tarea que sólo podían realizar bistoriadores con autoridad moral y cientifica...". 39

Cuestiones interesantes se suscitaron también durante el intercambio posterior a las exposiciones. Por un lado, se presentaron y aprobaron una serie de recomendaciones destinadas a fortalecer la enseñanza de la historia y la geografía en el nivel medio a través del aumento de la carga horaria y su dictado en gabinetes especiales con material pedagógico adecuado. También a través de propuestas de cambio en la formación docente, cuya centralidad en la transmisión de contenidos no pasaba desapercibida para los historiadores. Entre ellas la creación de Institutos especiales o carreras universitarias para la formación del profesorado y la prioridad de estos egresados sobre los provenientes de profesorados de escuelas normales y formaciones afines para ocupar cátedras en el nivel medio. ${ }^{40}$

Otro conjunto de iniciativas se dirigió a estimular la cooperación interamericana. Uno de los puntos que más adhesión concitó fue la recomendación a los gobiernos americanos de suscribir el convenio internacional de revisión de libros de texto firmado entre Brasil y Argentina en 1933. También se consensuó estimular la formación en cada escuela media del continente de una biblioteca de historia y geografía americana, integrada por autores americanos, traducidos si fuera necesario. Estas proposiciones

38 Academia Nacional de la Historia 1938, II Congreso Internacional de Historia de América, Buenos Aires, TV, pp. 430.

39 Ibidem

40 Academia Nacional de la Historia 1938, II Congreso Internacional de Historia de América, Op. Cit., TI pp 429 
se completaron con el proyecto de crear un programa de becas para que jóvenes historiadores realizaran estancias en países de América, y la moción de insistir ante las instituciones universitarias y de formación docente para que las cátedras de historia de América pusieran énfasis en la historia americana contemporánea, pues se lo entendía como el medio más adecuado para la creación de un sentimiento de solidaridad continental. ${ }^{41}$

Este impulso en pos de acentuar el espíritu americanista a partir de lo común y propio, se conjugó sin dificultades con propuestas tendientes a reforzar el legado colonial, especialmente el hispánico, y en general, el valor simbólico de las potencias coloniales. Una de ellas comprometía los esfuerzos de los historiadores presentes en la creación de cátedras de historia de la civilización de España, Portugal e Inglaterra en las universidades de América donde no las hubiera; otra, iba dirigida a los ministerios de educación y a través de ellos a los docentes de los cursos de historia universal o de la civilización, para que dieran mayor importancia en sus programas a la historia de España. ${ }^{42}$ Las varias referencias a lo largo de la sesión a las ideas y obra de Rafael Altamira, un connotado representante del hispanoamericanismo español especialmente invitado al congreso, pese a que no concurrió por problemas personales-, también podría leerse en este sentido.

\section{Algunas consideraciones finales}

El II Congreso Internacional de Historia de América fue organizado por la Junta de Historia y Numismática Americana, una de las instituciones vertebradoras del novel campo historiográfico argentino de ese momento. Sin embargo, sus objetivos, organización y desarrollo lo posicionaron bastante más allá de los confines académicos. La propuesta académica se convirtió en una sutil herramienta de intervención política y diplomática en la que los historiadores, apoyados en la legitimidad de su saber promovieron una

41 Ibidem, pp. 428-432

42 Ibidem, pp. 428 
imagen del pasado americano que daba unidad al continente y situaba a los proyectos de corte panamericanistas en una deriva natural de ese proceso. En el complejo panorama político de entreguerras, el congreso, convertido en un evento oficial de carácter internacional, fungió como una verdadera embajada historiográfica al servicio de la cooperación internacional entre los países americanos en tanto se reivindicaba como expresión de la unidad histórica característica del continente. Es difícil medir el impacto de esta diplomacia cultural. La voluntad de impulsar proyectos de cooperación o incitar a acciones concretas de los gobiernos en el ámbito educativo y cultural es explícita en las conclusiones y recomendaciones resultantes del trabajo realizado por los historiadores durante el congreso. Ellas fueron elevadas a cada uno de los gobiernos de los países participantes que afirmaron apoyarlas -por lo menos discursivamente- y en algunos casos iniciaron gestiones para materializarlas, aunque en los años siguientes no se vislumbrarían grandes transformaciones en los modos de hacer y enseñar historia americana. En los organismos internacionales de la región la actividad no dejaría de tener resonancias. Un informe posterior al congreso elevado a la Unión Panamericana señalaba que “...La solidaridad panamericana, (...) tomó como resultado del Congreso una nueva y vital significación..."

La institucionalización progresiva de un evento de esta naturaleza, convertido por sus gestores en una institución permanente que se reuniría con periodicidad en distintas ciudades americanas, no solo promovería investigaciones originales sobre la historia americana y estimularía relaciones y actividades académicas entre historiadores e instituciones dedicadas a esos quehaceres. También conformaría una plataforma desde la que estimular acercamientos y acuerdos, sortear desavenencias diplomáticas o impulsar posicionamientos internacionales. La realización de las siguientes ediciones del congreso, concretadas en Buenos Aires en 1960 y 1966 en climas político culturales bien diferentes del existente en la coyuntura estudiada, muestran hasta qué punto la invocación a la capacidad prospectiva de la historia podía convertir espacios centralmente académicos como los congresos de historia en un instrumento para

43 Ibidem, pp. 515 
fundamentar científicamente sucesivas reconfiguraciones y deslizamientos de la identidad americana. 


\section{BIBLIOGRAFÍA}

Academia Nacional de la Historia. 1938, II Congreso Internacional de Historia de América, Buenos Aires.

Blänsdorf A. 2010, "Une collaboration scientifique 'dans un esprit vraiment œcuménique et international': Les congrès internationaux d'historiens et le Comité International des Sciences Historiques dans l'Entre-deux-guerres" en Revue Germanique Internationale, Núm. 12, pp. 209 a 228.

Cattaruzza A. 2001, "Descifrando pasados: debates y representaciones de la historia nacional" en Cattaruzza A. (Dir.) Crisis económica, avance del Estado e incertidumbre politica, Sudamericana, Buenos Aires.

Devoto F. 2019, "La Academia Nacional de la Historia en sus primeros ochenta años: entre tradición e innovación" en Investigaciones $y$ Ensayos, Vol. 67.

Devoto F. 2008, "La construcción del relato de los orígenes en Argentina, Brasil y Uruguay: las historias nacionales de Varnhagen, Mitre y Bauzà" en Altamirano, C. (Dir.) Historia de los intelectuales en América Latina, Katz, Buenos Aires.

\section{Erdmann K. 2005, Toward a Global Community of Historians: The International Historical Congresses and the International Committee of Historical Sciences, 1898- 2000. Kocka J. y Mommsen W. (Ed) in collaboration with Agnes Blänsdorf, New York, Berghahn Books.}

Girbal Blacha N. 1995, "Renovación y proyección nacional e internacional de la Junta. Ricardo Levene (1927-1931/1934-1938) y la gestión Ramón J. Cárcano y Carlos Correa Luna (1931-1934)" en La Junta de Historia y Numismática Americana y el movimiento bistoriográfico en la Argentina: 1893-1938, Buenos Aires, pp. 123 a 167.

Hübinger, G. Picht, B. \& Dabrowska, E. 2010, "Cultures historiques et politique scientifique. Les congrès internationaux des historiens avant la Première Guerre mondiale" en Revue germanique internationale, Núm. 12, pp. 175 a 191.

Levene R. 1912, Lecciones de Historia Argentina, Ed. Lajouane, Buenos Aires.

Levene R. 1932-36, Estudios de Historia Nacional. s/e.

Levene R. 1942, La Cultura Histórica, Espasa Calpe, Buenos Aires.
Levene R. 1940-1942, Historia de América, W. M. Jackson Inc, Buenos Aires.

Lewkowicz M \& Rodriguez M. 2016, "Historiografía académica e historia escolar. Los libros de texto de historia entre dos centenarios" en História da Historiografia,, Núm. 20, pp. 48 a 68.

Nascimento Júnior, J. L. 2018, “O congresso, os anais e a historiografia Apontamentos sobre I Congresso Internacional de História da América (1922)" en Revista Latino-Americana de História, Vol. 8, Núm. 20, pp 269 a 284.

Nascimento Júnior, J. L. 2019, “Congresso Internacional de História da América (1922): Redes de intelectuais e disciplinarização do conhecimento histórico" en Revista Maracanan, Núm. 21, pp 192 a 200.

Nascimento Júnior, J. L. 2019, “Considerações sobre a produção historiográfica no primeiro quartel do século XX a partir do I Congresso Internacional de História da América (1922)" en Intelligere, Revista de História Intelectual, Núm. 7, pp. 97 a 108.

Ortemberg P. 2014, "Los centenarios patrios en la construcción de alianzas y rivalidades internacionales: los festejos trasandinos de 1910, la estatua de O'Higgins y los bemoles peruanos" en Anuario de Historia de América Latina, Núm. 51, pp 329 a 350.

Ortemberg P. 2015, “Geopolítica de los monumentos: los próceres en los centenarios de Argentina, Chile y Perú (1910-1924)" en Anuario de Estudios Americanos, Núm. 72, pp 321 a 350 .

Paschoal Guimarães L. 2005, "Limites políticos de um projeto intelectual para a integração dos povos do Novo Mundo: o Primeiro Congresso Internacional de História da América (1922)" en Topoi, Núm. 10, pp. 192 a 212.

Pernet C. 2007, "La cultura como política. Los intercambios culturales entre Europa y América Latina en los años de entreguerras" en Puente@Europa. Noticias de Europa, noticias de América Latina, Año V, Núm. 3-4.

Pita González A. 2017, "Panamericanismo y Nación. La perspectiva de Samuel G. Inman" en Anuario IEHS, Núm. 32.

Rodriguez M. 2018, "De historiadores y de los posibles usos de su saber: la contribución de los Congresos Internacionales de Historia de América en la conformación de una identidad americana (décadas de 1930 a 1960)" en História da Historiografia, Núm. 27, pp.91 a 117. 
Sansón Corbo T. 2014, "Matrices institucionales y metodológicas de la historiografía rioplatense del siglo XIX. El influjo de Brasil" en Confluenze. Rivista di Studi Iberoamericani, Vol 6, Núm. 1, pp. 111 a 137.

Sansón Corbo T. 2015, Despertar en Petrópolis. Andrés Lamas y la influencia de Brasil en la Historia de los Estados de la Cuenca del Plata en el siglo XIX, Sicut Serpentes, Montevideo.

Suárez C. \& Saab J. 2012, "El Estado, Ricardo Levene y los lugares de la memoria" en Clio \&Asociados, Núm. 16.

UNESCO. 1951, La reforma de los manuales escolares y del material de enseñanza. Como ponerlos al servicio de la comprensión internacional, Paris. 